\title{
Empirical Study on Constitutional Interpretation in Judicial Field
}

\author{
Huafeng $\mathrm{Lu}$ \\ School of Political Science and Public Administration \\ University of Electronic Science and Technology of China \\ Chengdu, P.R China
}

\begin{abstract}
Although the Courts in China do not take the Constitution as the direct basis of judgment, the Court's pursuit of individual justice provides a considerable existential space for the interpretation of constitutionality. Legislation has generality and it is difficult to take the special features of social life into consideration, thus, when applicable, the occurrence of unfair judgment to individual cases is inevitable. Taking into consideration of individual justice, the Court will converse the law meaning in judgment, or abandon the usual explanation of the law and select an unusual explanation. This process is essentially a process of constitutional interpretation. Although the Supreme People's Court does not approve of the direct invoking of the Constitution in judicial judgment, the conversion of law meaning or the selection of interpretation scheme in the process of judgment objectively requires the Court to take the Constitution as the basis of argument. Resorting to the Constitution, after all, is better than the abstract idea of resorting to fairness and justice. By converting the question of judgment of individual justice into the question of whether the law is in conflict with the Constitution in its application process, the constitutional interpretation can not only provide constitutionally legitimate basis for judicial lawmaking, but also provide it with constitutionally control, which is conductive to the standardization of the judgment. Constitutional interpretation can also make up for the institutional gaps and omissions of constitutional review system of China.
\end{abstract}

Keywords-constitutional interpretation; court practice; law meaning conversion; constitutional review system

\section{INTRODUCTION}

As an interpretation method, constitutional interpretation is reflected in the constitutional examination process, and also penetrates into the judicial process of ordinary courts. In terms of its content, Swiss scholar Campische and N.Muller divide constitutional interpretation into three rules: the first one is the simple interpretation rule, which means that the related provisions of the constitution shall directly have influence in legal interpretation; the second one is the conflict rule, which means that legal interpretation conformed with the content of the constitution shall have the priority to be selected over several possible legal interpretations; the third one is the preservation rule, which means that when the law has several interpretations due to having unconstitutional doubts, the interpretation which is

\author{
Jiayuan Zhang \\ School of Political Science and Public Administration \\ University of Electronic Science and Technology of China \\ Chengdu, P.R China
}

not unconstitutional shall be selected. On this basis, Taiwanese scholar and Professor Su Yongqin of our country merges the second and the third rules into the "conflict rule", and forms the content of constitutional interpretation together with the first rule, i.e. the simple interpretation rule [1]. The initial form of constitutional interpretation is generally considered to come from the judgment made by Swiss Federal Court in 1908, in which it indicated that "The legal interpretation shall not go beyond the scope of the constitution, and this is the right approach of an interpretation" [2]. From the perspective of conceptual form, constitutional interpretation has presented diversity to some extent, for instance, it is called as "constitutional limited interpretation", "constitutional legal interpretation", and "constitutional interpretation", etc. [3]. The term is also of polysemy, for instance, many scholars understand it in the narrow sense in terms of content, that is to say, the simple interpretation rule is excluded out of the scope of constitutional interpretation, such as German scholars Larenz and Ruthers, etc. [4].

Discussion about constitutional interpretation method has been a hot spot of constitutional theory of our country since 2008. From the overall perspective, argument on this issue in constitutional academic circle is mainly carried out around constitutional interpretation system provided by Article 67 of Chinese Constitution. At the beginning of the discussion, constitutional interpretation method is considered as a legal interpretation principle. Although it is related to the Constitution, it is not a method that interprets the Constitution, instead, it is a method that interprets the law, and hence, it can be applied to the judgment of individual cases by the courts [5]. However, soon, it is discovered that interpreting the Constitution is the necessary link that the constitutional interpretation could not bypass, and then people turn to concentrate on the argument of the nature and structure of constitutional interpretation right provided by Article 67 of the Constitution: some scholars believe that under the current constitutional interpretation system of our country, courts have no right to interpret the Constitution, so constitutional interpretation will not exist in our country [6]; while more scholars are optimistic about this issue, and they either advocate that the Standing Committee of the National People's Congress is not vested with exclusive constitutional interpretation right by Article 67 of Constitution [7], or further divide the constitutional interpretation right into the 
abstract constitutional interpretation right and the concrete constitutional interpretation right, believing that the right of the Standing Committee of the National People's Congress vested by Article 67 of the Constitution refers to the abstract constitutional interpretation right, which will not hinder the courts from interpreting the Constitution in the judgment of individual cases, and the constitutional interpretation is naturally included [8].

Discussions of scholars about the constitutional interpretation method mostly attach importance to the abstract level of its concept and principle, and some focus on introducing foreign theories [9], but pay little attention on legal practice of our country. Perhaps, it seems to the constitutional academic circle that the concept and theory of constitutional interpretation is inherently exotic, and the task for the academic circle is to form the basic frame of constitutional interpretation theory in our country, recommend this legal technology to the practice circle, and "promote the judges to respond actively on academic advice" [10]. This seems to have overestimated the doctrinal capability, and depreciated the judicial wisdom in practice. In a sense, the vitality of a legal theory or a legal method is rooted in the indigenous legal practice, but not its prosperity in the exotic. As a matter of fact, courts at all levels of our country have frequently handled cases applying the constitutional interpretation method unwittingly. The academic circle should reorganize and analyze this judicial practice and make summarization in methodology. Actually, as long as observing the courts' practice of our country closely, many abstract disputes over constitutional interpretation method among scholars may not be an issue at all.

For this reason, this article will not intend to repeatedly justify over constitutional interpretation method theoretically, and will try to conduct preliminary analysis and conclusion on constitutional interpretation practice occurred in judicial judgment of our country. On the one hand, it is the reorganization on the practice; on the other hand, it is a test for constitutional interpretation theory. Perhaps only after being tested by indigenous practice, can the exotic constitutional interpretation theory take root and grow healthily. Of course, from the factual level, courts of our country seldom cite the Constitution directly, and the Supreme People's Court also has expressed or implied to the courts of all levels that it is not suitable to cite the Constitution directly. Hence, whether the application of constitutional interpretation method is indeed applied to the judicial judgment of our country is the first problem needed to be faced.

\section{INDIRECT CONSTITUTIONAL INTERPRETATION}

In accordance with the Constitution and other constitutional legal documents, the Supreme People's Court can neither accept any constitutional litigation, nor examine whether the applied law is constitutional in ordinary lawsuits. Therefore, the aim of directly applying the Constitution or handling constitutional litigation cannot be achieved by the constitutional interpretation of the law. The Constitution of our country does not stipulate the jurisdiction of court cases, and Article 123 of the Constitution only stipulates that the courts are the judicial organs of the state, and does not stipulate the jurisdiction of court cases. The case jurisdiction of courts is stipulated by procedural laws, and the courts shall try civil, criminal, and administrative cases as prescribed by law. Procedural laws do not have the right to stipulate the courts having jurisdiction over constitutional cases; therefore, constitutional litigation is not included within the scope of courts' jurisdiction. The Supreme People's Court has issued a document clearly stipulating that people's courts of all levels may not accept any cases of "constitutional lawsuits", may not introduce the Constitution into litigation procedure, and may not change the function disposition of the state organs stipulated by the Constitution; when trying cases, people's courts may not cite provisions of the Constitution in the judgment documents [11]. No courts will accept constitutional litigation, means that the courts can't try and make any adjudication over the constitution of laws; in the meantime, examinations of the courts on normative documents in administrative litigation can only be examinations of legitimacy, instead of examinations of constitution. Since the courts will not accept constitutional litigation, with no authorization clearly expressed by the Constitution or the laws, there is no need to comment on the constitutionality of laws, and it is impossible to incidentally interpret constitutional norms when interpreting the laws.

Summing up the above, at the normative level, the Supreme People's Court has repeatedly expressed or implied to the courts of all levels that it is not suitable to cite the Constitution directly in the judgment [12]; while at the practical level, although it happens occasionally that the courts cite articles of the Constitution in the judgment documents, most courts deliberately evade the constitutional concept in the judgment, even sometimes may be so deliberate to have left traces [13]. Since constitutional interpretation can't be separated from the interpretation of the Constitution and courts of our country will not cite directly or interpret the Constitution, let alone the detailed description of interpretation methods, so it seems hard to say that there is constitutional interpretation in the judicial judgment.

Nevertheless, constitutional interpretation is good at being invisible in practice, and can be recognized after being analyzed carefully. Federal Constitutional Court of Germany often illuminates the applied legal interpretation methods in the judgment documents, but it is rather than an exception, and the judgment department usually does not illuminate its interpretation methods in the verdicts. With his practical experience, $\mathrm{Wu}$ Geng pointed out that constitutional interpretation has the feature of hiding its light under a bushel, and most of the time "you can find a clue only depending on the interpretation of the scholars" [14]. So, where can we find a clue of constitutional interpretation operated by the courts of our country? Let us view the judgment opinion of the following case.

Case No.1: Case of Qi Yuling. In 1990, Qi Yuling, the plaintiff, and Chen Xiaoqi, one of the defendants, are both junior middle school students of Tengzhou No. 8 Middle School in Shandong province, and both participated in the 
preliminary examination for secondary specialized schools. Chen Xiaoqi failed to pass the preliminary examination, and was not qualified for participating in the unified entrance examination. While, after having passed the preliminary examination, Qi Yuling scored higher than the admission line for the student of entrusted training. Shandong Ji'ning Commercial School sent Qi Yuling the letter of admission, which is transferred by Tengzhou No. 8 Middle School. Chen Xiaoqi got Qi yuling's letter of admission from Tengzhou No. 8 Middle School. Under the plan of Chen Kezheng, her father, using various methods, Chen Xiaoqi attended school of Ji'ning Commercial School in the name of Qi Yuling until graduation. After graduation, Chen Xiaoqi worked at Bank of China Tengzhou Branch in the name of Qi Yuling. The plaintiff alleged that because of the falsification jointly made by the defendants, Chen Xiaoqi, the defendant, was facilitated to have studied in Ji'ning Commercial School falsely using the name of the plaintiff, causing the right of personal name, the right of being educated, and other related interests of the plaintiff being violated. The plaintiff requests the court to order the defendant ceasing the infringement act, making apologies, and compensating the economic loss of the plaintiff of 160 thousand yuan, emotional loss of 400 thousand yuan. After the hearing, the court deems that the dispute point of this case lies in whether the act of the defendant constitutes infringement over the right of being educated of Qi Yuling. The right of being educated alleged by Qi Yuling, the plaintiff, belongs to the category of general personality right of the citizens. It is a free right for the citizens to enrich and develop their own personality. But, evidence of this case shows that Qi Yuling has actually given up this right, that is the chance for attending the school for student of entrusted training. The evidence that her right of being educated has been violated she alleged is insufficient, and is unsustainable. There is no causality between the compensation of each material loss requested by Qi Yuling based on this allegation and the infringement act of Chen Xiaoqi, the plaintiff, so the allegations thereof shall not be affirmed. Finally, the court ordered that the defendant shall bear the responsibility of infringing the right of being educated of the plaintiff, which is the first case of judicialization of constitution of our country. Although it does not directly mention the citation of the right of being educated stipulated by the Constitution, indirectly, complying with the provision of General Principles of the Civil Law, the defendant is convicted of infringement. In this case, the court enlarged the expressive form of infringement act with the particularity of the right of being educated, which is beyond the frame of the civil law, and has introduced constitutional consideration of higher hierarchy. This can be regarded that the court conducted a constitutional interpretation to the General Principles of the Civil Law based on the intension that the right of being educated is protected by the Constitution.

\section{LITERAL INTERPRETATION-BASED ON THE EXTENSIVE AND RESTRICTIVE METHODS}

When interpreting the law, if it relates to extending or restricting civil rights, or limiting the exercise of the civil rights, or relates to the constitutional issues such as the application of international treaties in China, the Supreme People's Court shall interpret the constitutionality of the said law or judicial interpretation, and generally shall cite articles of the Constitution in the judicial interpretation. It illustrates the constitution of laws based on the constitutional principle and spirit. For instance, in Interpretation on Several Issues in the Implementation of the Administrative Procedure Law issued by the Supreme People's Court, the interpretation on litigious right of the parties of Article 1, and the interpretation on related provisions of the application of civil law regulations when civil disputes are tried jointly of Article 19. All of the interpretations relate to the guarantee issue for basic rights of the parties. Article 12 of Administrative Procedure Law limits the scope of accepting cases of the courts, and Articles 25 and 49 limit the prosecution requirements. The prosecution right belongs to the basic rights. If any administrative actions infringe the right of the administrative counterpart and cause damage, limited by the scope of accepting cases of the Administrative Procedure Law, the prosecution right will not get the judicial protection. At this point, the Supreme People's Court must interpret the constitutionality of Administrative Procedure Law based on the principles and spirits of the Constitution and combining the feature and technology regulations of administrative litigation. As a matter of fact, the Supreme People's Court has made interpretation beneficial to human rights guarantee over the limited articles related to the basic rights in Administrative Procedure Law based on the principles and spirits of the Constitution. These interpretations are substantial legal constitutional interpretations, only without using the name or form of legal constitutional interpretation.

Literal interpretation is an important method of constitutional interpretation, and in most cases, it hides under the restrictive or extensive representation of teleology. Conversely, restriction or extension of teleology is often accompanied by transformation on legal literary content. For instance, Federal Constitutional Court of Germany restricted service in the army of Exemption from War Service Law to "non-armed service without weapons" [15], and restricted assembly in the Assembly Act to assemblies excluded from temporary fortuitous assembly [16]. The above examples show the close relation between constitutional interpretation and teleological interpretation. Therefore, although people hold different opinions on the nature of constitutional interpretation, which is defined as one kind of teleological interpretation [17]; even for the same case, some people classify it as teleological interpretation (actually, it should belong to teleological restriction), and some people make it an example of constitutional interpretation [18]. Since this kind of constitutional interpretation has already restricted or extended on legal literary content to some extent, which is beyond the literary content scope of the law, and belongs to further development of the law, it can also be called further development of constitutional laws [19].

Case No. 2: Hou Bo from Beijing kept Ming Ming, his son, at home, and educated Ming Ming himself, and made Ming Ming's performance at English and reading go beyond the ability of children of the same age, and Ming Ming can 
even read classical literature and English Newspapers; however, Wang $\mathrm{Yu}$, his ex-wife, holds the opinion that not receiving formal education from school is bad for the future growth of Ming Ming, so she appeals to the People's Court of Beijing Shijingshan District to get the guardianship of Mingming. On September 19, 2006, after the hearing, the court deems that although home education is more pertinent to individual student, after all, it is not systematic or comprehensive. Cultural course is only a part of compulsory education, and compulsory education refers to moral education, intellectual education, physical education, aesthetic education, labor education, and social life guidance as well as adolescence education to minor students. The family and school shall coordinate with each other, keep close touch with each other, pay attention to individual differences of students, teach students in accordance with their aptitude, and promote the full development of the students. Compulsory Education Law of the People's Republic of China explicitly stipulates that "compulsory education is the education which is implemented uniformly by the State and shall be received by all school-age children and adolescents", "any child who has attained to the age of 6 , his/her parents or other statutory guardians shall have him/her enrolled in school to finish compulsory education". Based on this, receiving national compulsory education is Ming Ming's right, and is also the legal obligations that shall be fulfill by the defendant Hou Bo. Hou Bo shall solve the problem of Ming Ming's attending school, and have him receive comprehensive compulsory education.

Judging from the judgment of the court in this example, the judge of this case did not "arbitrarily" negate the home education of Hou Bo applying Compulsory Education Law, instead the judge reasoned moderately to prove the education of Hou Bo was not equivalent with the school education, which deserves praise. Paragraph 1, Article 46 of the Constitution stipulates that citizens of the People's Republic of China have the duty as well as the right to receive education. This kind of expression makes receiving education embodied as a basic right of the citizens, and also embodied as a basic duty of the citizens. In this case, the judge extended the expression form of the receiving education right and the receiving education duty by the method of literal interpretation, which shall be the receiving education right and the receiving education duty at school, instead of at home. There are a great many of cases of extension or restriction of teleology in the field of civil laws, such as the extending "younger brothers and sisters who are minors" of Article 29 of Marriage Law to "younger brothers and sisters who are adult" [20], and extending "A mentally ill person" of Article 13 of the General Principles of the Civil Law to "person in persistent vegetative state" [21]. The application of constitutional interpretation method is hidden in these judgments, and it is unnecessary to go into details here.

\section{CONSTITUTIONAL INTERPRETATION BASED ON TELEOLOGY}

When the literal interpretation cannot achieve selfconsistent answers, interpreter can also turn to the teleological interpretation which "provides the largest free space for legal persons, and makes 'the rational of his own' works". The teleological interpretation is known as an objective interpretation method, which cares the "objective will" of the law, instead of the "subjective will" of the legislators, and its basic mechanism believes that the laws may be more brilliant than the legislators. Concretely speaking, in several interpretation versions of the laws, some have unconstitutional doubts, some do not. At this point, the court shall choose the interpretation version that does not have unconstitutional doubts with the Constitution as the criterion.

Case No. 3: Yu Li V. Sina. In this case, based on the agreed conditions, Sina unilaterally terminated the contract with Yu Li. People's Court of Beijing Haidian District did not decide the termination of the contract being valid according the literal content of the provisions of the Contract Law, but added extra conditions to the termination of the contract, and substantially declared that Sina shall not terminate the contract. Of course, when expounding the grounds of the decision, People's Court of Beijing Haidian District did not cite the Constitution as the grounds of the decision. In nature, the decision of the court can be considered as the teleological restriction on the literal content of the provisions of the Contract Law based on the constitutional considerations, which belongs to the application of constitutional interpretation method.

There are more than a few judgments of alternative suitable nature in the field of civil laws. For instance, interpret the application system of declaration of death stipulated in Article 23 of General Principles of the Civil Law as that if the interested person of the previous order does not exercise the application right maliciously, then the interested person of the second in order may apply; interpret the "victim" stipulated in Article 106 of General Principles of the Civil Law as including not only the direct victim, but also the indirect victim; interpret the provisions that the limitation of action can be discontinued "if suit is brought" in Article 140 of General Principles of the Civil Law as that the limitation of action can be discontinued even if suit is brought against the non-infringer; interpret the "the movables of the obligor" as all the movables not only owned by the obligor, but also possessed legally by the obligor; interpret the "textbooks" stipulated in Article 23 of the Copyright Law as textbooks excluding teachers' books, etc. These are all teleological interpretations within the scope of literal content of the laws, implying the application of constitutional interpretation.

After analyzing the current three main methods of court constitutional interpretation in judicial practice of our country, let us return to the text of the Constitution to rethink the constitutional interpretation. It is stipulated in the preamble of the Constitution that "all state organs... have the duty to uphold the dignity of the Constitution and ensure its implementation", which seems to declare that all state organs including courts have the specific duty to enforce the Constitution. However, Article 67 of the Constitution stipulates clearly that the Standing Committee of the National People's Congress shall "interpret the Constitution, 
and supervise the enforcement of the Constitution". Legislation enforcement maybe the main channel of the application of the Constitution, and the constitutional interpretation of the courts is just a branch of the trunk, which is the supplement of the application of the Constitution. Since the legislation is of universality and generality, cannot give consideration to all aspects of the social activities, and it is impossible to avoid the problems that the result of individual cases is unfair in the application process. If applied directly, not only the expected goal of legislation cannot be reached, but also will cause more social chaos. Therefore, the specific implementation of legislation needs the mechanism of "practical concordance", and it is the function of the constitutional interpretation. On the whole, the constitutional interpretation is the process that the value order represented by the Constitution dissolves downward in the complete set of the legal system. The Constitution and department laws adapt each other during this process, and maintain a legal order where there is order in the motion.

The practice of the constitutional interpretation carried out by the courts provides an opportunity and a challenge for the constitutional theory refinement of our country. When the courts carry out the constitutional interpretation, whether literal interpretation or teleological interpretation, all shall take the Constitution as criterion, then the concrete problem of how to interpret the Constitution emerges. We may infer that if the constitutional theory cannot form a more concrete opinion on constitutional interpreting problems, it will be very difficult to provide doctrinal support for the constitutional interpretation of the courts. It can therefore be said that the operation of constitutional interpretation of the courts objectively needs refinement of the constitutional theory.

The practice of constitutional interpretation of the courts also needs the interdisciplinary integration between the Constitution and the department laws. Since the constitutional interpretation occurs in the concrete implementation process of the department laws, the constitutional theory needs to pay attention to the concrete implementation of the department laws as well as the development of the theory of department laws; otherwise, it will be difficult to provide sufficient doctrinal judgment on the practice of the courts. The constitutional interpretation cases reorganized by this article are mostly in the field of the civil laws. Some of them relate to mandatory regulations, while some of them relate to arbitrary regulations. These two kinds of regulations have different meanings to the protection of basic rights, for instance, mandatory regulations mostly relate to interference of the basic rights, while arbitrary regulations mostly relate to deficiency of protection of the basic rights. If the civil law theory relating to this is not mastered, it will be very difficult to interpret the constitutional problems thereof.

By reorganizing the practice of the courts, this article describes the objective existence of the constitutional interpretation methods in the judicial judgment of our country, and briefly argues its inevitability. Indirect interpretation, literal interpretation, and teleological interpretation constitute the basic methods of the constitutional interpretation of the courts of our country. Limited to the space and the theme, this article does not fully discuss and criticize the practice described in the normative sense. Undoubtedly, the practical application of the constitutional interpretation methods of the courts of our county is not completely without problems. Theoretically speaking, the constitutional interpretation relates to power distinction between legislation and judicature. Moderate constitutional interpretation may be reconciled with legislation and "help the legislation out of slackness", but excessive or improper constitutional interpretation may distort functional distribution, and this is no longer the case that "the most suitable person makes the most appropriate decision". Especially for the constitutional interpretation of literal transformation type, when it is operated by the courts, it may break through the obvious literary content of the law, "constitutional interpretation" in this sense is even in danger of arrogating the legislation, and its frequent occurrence will be the unbearable burden of the courts of our country. Certainly, the academic circle has discussed the limit of the constitutional interpretation, as some scholars pointed out that Federal Constitutional Court of Germany has repeatedly declared that the constitutional interpretation shall not go beyond the specific literal content of the laws, and there are also similar statements in America. Nevertheless, how to judge the practice of the courts of our country, discuss the problems thereof, and analyze the causes of these problems as well as its improving direction from the general position in theory, will remain an important task in the academic circle. German scholar Professor Bettermann holds the opinion that "constitutional interpretation" is a kind of "interpretation method in the guise of other's, or of imposture", or rather is an "incorrect wording". Through the above analysis, it can be seen that this kind of inference is understandable but rather too extreme, and neglects the methodologically supplemental function of the constitutional interpretation to a large extent. Based on the difference between general judicial power and constitutional reviewing power, the constitutional interpretation must be carried out from the two levels of legal method and constitutional method. As a selecting rule of a method, it becomes a principle method in the practice under the rule of law of various countries because it roots in the common checks and balances between judicature and legislation under modern decentralization system. Of course, it may be possible that although the court implies the unconstitutional possibilities of legislation through constitutional avoidance doctrine, and promotes the legislative branch to correct legislative restoration, but the legislators work delinquently and will not correct the unconstitutional possibilities thereof, instead, "taking retreat in order to advance" they take the temporary judgment of the court as the final conclusion. In this way, the constitutional problems are not avoided at all, and new potential constitutional problems will come into being. For this possible situation that legislators work delinquently, we shall take action to bring it under control trough organic systems such as legislation supervision, social supervision, and proposals of people's deputies, etc., and eliminate the delinquency of the legislators. The mission of judicial persons lies in respecting the legislators to a large extent, and 
trying to return the task originally belonging to the legislators to the legislators.

\section{CONCLUSION}

Based on court practice, this paper describes the objective existence of the constitutional interpretation in judicial trial of China and demonstrates its inevitability. Due to the length and subject matter, this paper does not elaborate and criticize the described practices in a normative sense. There is no doubt that the practical application of constitutional interpretation by the courts in China is not entirely unproblematic. Theoretically, constitutional interpretation involves the distinction between legislative and the judicial powers. Moderate constitutional interpretation may be able to reconcile legislation and "address slack legislation". However, excessive or improper constitutional interpretation may distort functional distribution and thus will no longer mean "the most appropriate decision made by the most appropriate person". Especially for the constitutional interpretation of law meaning conversion, this "constitutional interpretation" is likely to override legislation as the court may break through the obvious legal literary meaning in the operation. This practice of constitutional interpretation, if occurring frequently, will be something that the courts in China cannot bear. Indeed, the academic circle discusses the boundary of constitutional interpretation. According to some scholars, for instance, the Federal Constitutional Court of Germany has repeatedly stated that constitutional interpretation cannot go beyond the clear legal texts, and similar statements are also made in the United States. However, it is an important task for the academic circle to judge the practice of the courts in China from the general proposition in theory, to discuss the existing problems and to analyze the causes and improvements.

\section{REFERENCES}

[1] Professor Su Yong-qin believes that it will be clearer to divide the constitutional interpretation rules into two levels, i.e., to merge the preservation rule with the conflict rule, and then adopt the dichotomy of "interpretation rule" and "conflict rule". Su Yongqin, "Theory and practice of constitutional control, " Taiwan Yuedan Press, 1994:84. (in Chinese)

[2] Su Yong-qin, "Theory and practice of constitutional control," Taiwan Yuedan Press, 1994:79. (in Chinese)

[3] Zhai Guo-qiang "Method of constitutional judgment" Law Press, 2009:47; Xie Wei-yan, "On constitutional interpretation is not the judicial application method of constitution," China Legal Science, 2009 (6); [GER] Klaus Schlaich and Stefan Korioth, "Federal Constitutional Court of Germany: status, procedure, and judgment," Liu Fei Trans., Law Press, 2007:455. (in Chinese)

[4] [GER] Karl Larenz, "Methodology of law," Chen Ai-e, Trans., Taiwan Wu-Nan Book Inc., 1996:242; Wu Geng, "Politics and law theory \& jurisprudence method," China Renmin University Press, 2007:362; [GER] Ruthers, Jurisprudence, Ding Xiao-chun and Wu Yue-ze Trans., Law Press, 2005:326; Han Da-yuan, "On constitutional presumption in constitutional interpretation procedure," Tribune of Political Science and Law, 2003(2). (in Chinese)

[5] Zhang Xiang, "Two constitutional cases-possible impact of Constitution on judicature judging from constitutional interpretation," China Legal Science, 2008(4):110; Shangguan Pi-liang, "Path and method of current constitutional jurisdiction of China," Modern Law
Science, 2008(2):3; Wang Shu-cheng, "Constitutional interpretation method," Chinese Journal of Law, 2012(5):54. (in Chinese)

[6] Liu Lian-jun, "What is the meaning of constitutional interpretation: nature, legitimacy, restriction, and application," Journal of Swupl, 2010(4):62. (in Chinese)

[7] Huang Hui, "Constitutional interpretation and theory review thereof,' China Legal Science, 2014(1):295; Wang Kai, "Introspection of constitutional interpretation," The Jurist, 2015(1):52. (in Chinese)

[8] Huang Ming-tao, "Dividing line of two constitutional interpretation concepts and possibility of constitutional interpretation," China Legal Science, 2014(6):294. (in Chinese)

[9] Liu Jian-long, "Reality and argument of constitutional interpretation principle," Tsinghua University Law Journal, 2011(1):108. (in Chinese)

[10] Huang Hui, "Constitutional interpretation and theory review thereof," China Legal Science, 2014(1):288. (in Chinese)

[11] Wu Zhao-xiang, "Comprehension and Application of Provisions on 'Citing Normative Legal Documents such as Laws, Regulations in Adjudicative Documents' [J]," The People's Judicature, 2009(23). (in Chinese)

[12] Reply about "Constitution Shall not be Cited as Gist Of Judgment and Sentence in The Criminal Judgments" issued by the Supreme People's Court in 1955, Reply about "How to Cite Normative Legal Documents in Making Legal Documents for People's Courts" issued by the Supreme People's Court in 1986, "Provisions of Citing Normative Legal Documents Such as Law and Regulations in The Judgment Documents" issued by the Supreme People's Court in 2009 (in Chinese)

[13] For instance, in the case of Yu Li V. Sina, personal micro blog of the party is shut by Sina, which clearly involves freedom of speech of Article 35 of the Constitution, however, the expression selected by the court is "dissemination of legal information" (see civil judgment of People's Court Beijing Haidian District (2011) Hai Min Chu Zi No. 26297). For analyses of constitutional interpretation method involved in this case, see Du Qiang-qiang, "On Constitutional Interpretation of Arbitrary Regulation of Civil Laws," J East China Univ Political Sci Law, 2014(6):30. (in Chinese)

[14] Wu Geng, "Politics and law theory \& jurisprudence method, China Renmin University Press, 2007:368. (in Chinese)

[15] Wu Geng, "Politics and law theory \& jurisprudence method, China Renmin University Press, 2007:364. (in Chinese)

[16] Wang Kai, "Introspection of constitutional interpretation," The Jurist, 2015(1):52. (in Chinese)

[17] Su Yong-qin, "Theory and practice of constitutional control," Taiwan Yuedan Press Incorporated Company, 1994:85. (in Chinese)

[18] Wu Geng, "Politics and law theory \& jurisprudence method," China Renmin University Press, 2007: 325; Su Yong-qin, "Theory and practice of constitutional control," Taiwan Yuedan Press Incorporated Company, 1994:85. (in Chinese)

[19] Su Yongqin, "Theory and practice of constitutional control," Taiwan Yuedan Press Incorporated Company, 1994:85 (in Chinese)

[20] For "Zhou Rongchi, et al. v. People's Insurance Company of China Nanjing Branch, case of Wu Changbao traffic accident damages compensation dispute", see Selected Cases of People's Courts-Monthly Edition (vol.12), edited by Chinese Applied Law Science Research Institute, China Legal Publishing House, 2010:64. (in Chinese)

[21] For "Case of Luo Shilin applies for a declaration that Luo XX who is in persistent vegetative state is a person without capacity of civil conduct", see Selected Cases of People's Courts (vol.51), edited by Chinese Applied Law Science Research Institute, People's court press, 2005:144. (in Chinese) 